\title{
Reflexiones sobre la noción de catálogo y colección editorial. Dispositivos y estrategias para la producción de sentidos en el mundo del libro
}

Costa, María Eugenia; Garone Gravier, Marina

Reflexiones sobre la noción de catálogo y colección editorial. Dispositivos y estrategias para la producción de sentidos en el mundo del libro

Palabra Clave (La Plata), vol. 9, núm. 2, 2020

Universidad Nacional de La Plata, Argentina

Disponible en: http://www.redalyc.org/articulo.oa?id=350562513009

DOI: https://doi.org/10.24215/18539912e082

Esta obra está bajo una Licencia Creative Commons Atribución-NoComercial-Compartirlgual 4.0 Internacional. 
Dossier: Catálogos y colecciones editoriales en Latinoamérica: abordajes teóricos, históricos y materiales

\section{Reflexiones sobre la noción de catálogo y colección editorial. Dispositivos y estrategias para la producción de sentidos en el mundo del libro}

\author{
María Eugenia Costa \\ Instituto de Investigaciones en Humanidades y Ciencias \\ Sociales (Universidad Nacional de La Plata CONICET). \\ Facultad de Humanidades y Ciencias de la Educación \\ (FaHCE). Universidad Nacional de La Plata (UNLP), \\ Argentina \\ mcosta@fahce.unlp.edu.ar \\ (iD http://orcid.org/0000-0003-0167-3269 \\ Marina Garone Gravier \\ Universidad Nacional Autónoma de México. Instituto de \\ Investigaciones Bibliográficas. Seminario Interdisciplinario \\ de Bibliología, México \\ mgarone@unam.mx \\ iD http://orcid.org/0000-0002-5981-9243
} DOI: https://doi.org/10.24215/18539912e082
Redalyc: http://www.redalyc.org/articulo.oa?
id $=350562513009$
Recepción: 15 Marzo 2020

Aprobación: 31 Marzo 2020

El presente dossier "Catálogos y colecciones editoriales en Latinoamérica: abordajes teóricos, históricos y materiales" es resultado de la convocatoria para pensar, desde diversas orientaciones disciplinares y metodológicas, dos elementos que han sido centrales en la construcción de programas editoriales: colección y catálogo editorial. Los textos que componen esta publicación abordan objetos de estudio particulares: 1) una biblioteca americanista rioplatense (Valinoti); 2) una colección popular brasileña de corte universalista compuesta por libros de bolsillo (Ribeiro y Karam); 3) un repertorio de catálogos editoriales del Fondo de Cultura Económica (Garone Gravier); 4) una colección literaria de dicha empresa mexicana (Cervantes Becerril); y 5) un fondo editorial producto de un emprendimiento estatal en una provincia argentina (Bertuzzi).

A quien emprenda la lectura detenida de estos artículos de investigación y ensayos académicos se le plantean algunas reflexiones que se pueden articular a partir de estos dos conceptos polisémicos colección y catálogo editorial - los cuales, gracias a su potencial heurístico, permiten repensar en términos analíticamente productivos la historia del libro y la edición e historia de la lectura en América Latina, en un amplio arco temporal que abarca desde el siglo XIX hasta los albores del siglo XXI. Para el abordaje de estos conceptos-clave se tienen en cuenta cuatro núcleos de análisis interrelacionados.

En primer lugar, la colección editorial puede concebirse como una forma de compilación, una propuesta de ordenamiento de obras de diversa índole, las cuales se presentan relacionadas dentro de un conjunto asequible y coherente, integrado mediante la apelación a cierto denominador común. Si bien la disposición de una colección de libros establece un patrón que permite unificar al conjunto, en algunos casos presenta subdivisiones en secciones o series, que pueden tener manifestaciones materiales y visuales, por ejemplo diferenciadas por códigos cromáticos o el uso de algún elemento gráfico distintivo, un formato dado o el empleo de un papel especial. Como instancia clasificatoria, la colección editorial permite develar distintos modos de categorización y jerarquización de los contenidos. Los agrupamientos suelen basarse en 
determinados géneros discursivos o literarios, movimientos estéticos, corrientes ideológicas, escritores afines, procedencias espaciales o nacionalidades, recortes temporales, lenguas de traducción, temáticas específicas, rangos etarios del lectorado e incluso formatos. El lugar o la ubicación de un autor u obras dentro de una colección puede sustentarse en proyectos editoriales u otras prácticas de intervención cultural fruto de complejos procesos de reinvención de la tradición, popularización, 'clasicización', patrimonialización o canonización, ya sea a escala local, nacional o "universal". En uno de los trabajos del dossier que se titula "Coleçôes de livros de bolso no Brasil: notas sobre a Biblioteca Universal Popular", Ana Elisa Ribeiro y Sergio Káram emprenden el análisis sobre una colección editorial reunida bajo el criterio del formato de bolsillo, subdividida en series o subcolecciones. Esta económica biblioteca reunió un conjunto de ochenta títulos sobre temas considerados homogéneos por el editor.

Es de destacare, para analizar el armado de una biblioteca o colección editorial — potencialmente expandible - el eje vertebrador e integrador no siempre se encuentra definido de forma explícita ni es equivalente a la sumatoria de sus elementos constitutivos, ya que cada uno de los títulos seleccionados se transfiguran como unidades dentro un corpus que los reencuadra o circunscribe, los condiciona y limita, a la vez que instaura su propio contexto de producción de sentidos. De ahí la importancia de reconstruir la significación u orientación del conjunto y formular un reencuadre que torne legible las obras particulares y el corpus que forma una biblioteca o colección en su conjunto. La incorporación de una obra dentro de cierta colección general o especializada -con su respectivo título, sea descriptivo o metafórico- constituye una estrategia editorial que le confiere una nueva identidad reconocible a la heterogeneidad de textos contiguos que la integran. En el seno de la colección editorial se clausura la condición espacio-temporal originaria de los textos y se instaura una nueva categorización del repertorio textual, que atiende tanto las inclusiones como las exclusiones. De esta manera - parafraseando al reconocido historiador Roger Chartier (1994) — se configura y visibiliza un 'orden de los libros' preestablecido dentro de determinada 'puesta en serie'.

En cada colección de libros se establecen criterios de selección y modalidades de clasificación que, generalmente, provienen de quienes ocupan el papel de editor, asesor literario o director de colección, con sus respectivos perfiles socio-profesionales, trayectorias editoriales y posturas político-ideológicas que tensionan las elecciones adoptadas. La conformación del catálogo de un sello con asesores o directores que avalan las colecciones a su cargo puede leerse como un signo de profesionalización del sector editorial. Los criterios de seriación de los títulos publicados son fruto de operaciones culturales y se vinculan a los posicionamientos con respecto a los diversos campos editoriales. En el ensayo "Las metamorfosis de la Colección Tezontle. El primer catálogo literario del Fondo de Cultura Económica” la investigadora mexicana Freja Ininna Cervantes Becerril plantea que, durante el período 1940-1965, la transición de sello independiente a una "colección pragmática" del Fondo de Cultura Económica (FCE) no se explica tan solo por las políticas culturales de los primeros directores del sello, sino que se relaciona con las prácticas de edición literaria de algunos autores.

Por una parte, los agentes editoriales, ya sean privados o estatales, atentos a los préstamos e intercambios con modelos propios o foráneos, definen los parámetros de selección de los autores las formas de publicación de las obras que ingresan al catálogo, encargan las traducciones directas de los originales, convocan a ciertos artistas-ilustradores, deciden el diseño y la maquetación de los volúmenes, entre otras labores profesionales, y esa carga de actividades varía de acuerdo con la escala y perfil de la empresa editorial. Los criterios de corte selectivo - ya sean intelectuales, políticos, estéticos o económicos - se vinculan con la función específica consignada a la colección editorial y a la declaración programática deintenciones, sea esta explícita o implícita. Los fines o propósitos de la edición de colecciones pueden ser moralizantes, pedagógicos, instructivos, nacionalizantes, recreativos, entre otras funciones. Por otra parte, los editores se responsabilizan de incorporar los paratextos, verbales e icónicos, a cada ejemplar, como también se ocupan de desplegar diversas estrategias para publicitar las series en los medios de comunicación, periodísticos o en otros formatos y promocionar su venta apelando a distintos recursos publicitarios. 
La serialidad de la colección — regida por el mencionado principio ordenador que le da existencia y le otorga significado- se puede entender como una operación de reunificación, como una ensambladura que pone en relación dialógica a los componentes individuales. Más allá de la faceta económico-comercial, el valor simbólico conferido a obras de distintos géneros se materializa, entre otros factores, por su incorporación en determinadas colecciones. En tales casos se concibe a la biblioteca o colección como una construcción selectiva de legitimidad editorial, asociada a ciertos imaginarios socioculturales que inciden no solo sobre la figura de autor, sino también en las representaciones acerca de los lectores de distintas edades de diversos grupos sociales.

En segundo lugar, la especialización del fondo editorial que conlleva el lanzamiento de una variedad de colecciones se vincula con una propuesta de dotación de lecturas para un público imaginado o creado. Si bien en diferentes períodos históricos ha variado la magnitud, diversidad y estratificación del lectorado, es necesario considerar que el mismo está sujeto a ciertos condicionamientos socioeconómicos y culturales que inciden en sus gustos e intereses. El efecto de sentido construido por la colección editorial interpela las expectativas de los integrantes de una determinada 'comunidad lectora', creando una demanda regular de los libros editados o de 'próxima aparición', algunos de los cuales, de hecho, nunca se llegan a publicar. En el artículo "Crónicas para una historia de la edición y la lectura en el siglo XIX. La Biblioteca Americana de Alejandro Magariños Cervantes" la autora, Beatriz Cecilia Valinoti, confronta las aspiraciones del plan general del editor con las escasas obras efectivamente publicadas en Buenos Aires y Montevideo entre 1858 y 1864. En su argumentación reflexiona acerca de la importancia concedida a los suscriptores-lectores para solventar la edición de la colección americanista y analiza la retórica empleada para persuadirlos. En ese mismo sentido, y apuntando específicamente al impacto del factor en la configuración de una colección, en la antes mencionada investigación de Ribeiro y Káram sobre la Biblioteca Universal Popular publicada entre 1963 y 1968 por la Editora Civilização Brasileira, el bajo costo de los libros de bolsillo para volverlos accesibles a un público lector más amplio fue un elemento constitutivo de esa propuesta editorial.

Por un lado, la 'puesta en serie' de los ejemplares físicos procura mantener el nivel de expectación y contribuye a afianzar la captación, la fidelización y la identificación de los lectores frente a una propuesta editorial. La mencionada declaración de intenciones permite entrever el perfil del lector-comprador al cual está destinada cada colección. Ya sea que porten o no la secuencia numérica, los volúmenes seriados colaboran con la recepción comercial y el consumo cultural. Por otro lado, el lanzamiento y el sostenimiento de una colección a lo largo del tiempo tiende a otorgarle a la editorial cierta presencia y visibilidad en los distintos mercados locales o transnacionales del libro. Asimismo, la diferenciación de colecciones le permite a una editorial competir con otras empresas, con el objetivo de captar e imantar a los potenciales lectores. Por último, una rotación de títulos de una colección a otra en el contexto de un determinado catálogo, permite no sólo reactivar y diversificar la oferta de lecturas sino que también permite modernizar su presentación. En suma, toda colección editorial busca no solo exhibir un conjunto coherente de textos, sino construir, a través de esa propuesta materializada en objetos, ciertos modos de leer.

En tercer lugar, la colección editorial se considera —en términos de Jean Braudrillard ([1969] 2004) - como un 'sistema de objetos' palpables y visibles que son colocados unos junto a otros, interpelados por características comunes o correspondencias, pero también por distinciones que subyacen a la serie contenedora. La diagramación de una colección en tanto práctica editorial, se manifiesta como un despliegue de cierta concepción estética y tratamiento formal, plasmados en la propia materialidad de los ejemplares impresos (papeles, elección de los formatos, encuadernaciones, portadas, variedades tipográficas, ordenación de las jerarquías textuales, diagramación, ilustraciones u ornamentos, etc.). El diseño editorial homogeniza, unifica e integra los componentes individuales de la serie de libros y refuerza el principio de clasificación y visibilización, brindando a los lectores y lectoras ciertos signos de identidad gráfica a través de logos e imagotipos, colores diferenciados, tapas distintivas, sobrecubiertas, páginas de guarda, entre otros elementos 
visuales. Por ejemplo en el trabajo sobre la colección literaria Tezontle del FCE,Cervantes Becerril destaca la belleza tipográfica, la sencillez y el refinamiento de las cubiertas realizadas por artistas del exilio español.

La colección asociada a una "marca editorial" pasa a formar parte de la cultura gráfica impresa de una sociedad en un momento histórico determinado. A través de su visualidad las colecciones se exponen a la mirada cómplice del público lector, ya sea en la vidriera de una librería, el estante del kiosco o el anaquel de una biblioteca. Por consiguiente, la mirada forma parte de la colección ya que la misma fue creada para ser vista.

En cuarto lugar, la colección encarna o materializa un proyecto editorial, a partir de su maquetación e inserción en un determinado catálogo. La noción de catálogo alude fundamentalmente a dos sentidos que, en los análisis de casos, generalmente se hallan superpuestos. El primero de ellos, de corte más bien valorativo, lo define como un montaje inteligible de carácter simbólico o asimismocomo un constructo guiado por principios ordenadores y sustentado por ciertas concepciones $\mathrm{u}$ orientaciones que signan el perfil y la idiosincrasia de un sello editorial. Cervantes Becerril destaca que el catálogo general de Tezontle, contrariamente a la referida idea de orden, posee el aspecto de un "inventario azaroso" fruto de la coyuntura.

Los catálogos editoriales se enmarcan en un sustrato político de la oferta cultural, se insertan en una red de relaciones sociales y comerciales específicas. Desde otro punto de vista, el catálogo constituye un recorrido u operación de lectura por parte de los agentes editoriales, como lo señala el estudioso de la edición española Fernando Larraz Elorriaga (2016) los catálogos pueden incluir ciertos marcadores de "tradición" o "modernidad" visibles en el discurso.

No obstante se conciba al catálogo como un programa editorial razonado, a nivel de su concreción, el mismo puede limitarse en la práctica por las condiciones de posibilidad y una variedad de dificultades encontradas. Por ejemplo en el artículo de Valinoti, a través del relato autorreferencial de Magariños Cervantes -titulado "Crónica de una Biblioteca"- se reconstruyen los antecedentes y las circunstancias que originaron el proyecto editorial de la colección americanista, también se detallan como contrapartida los derroteros y las vicisitudes en la conformación efectiva del catálogo. Por su parte, Mauricio Carlos Bertuzzi en su ensayo "Politica de Estado en edición de libros en la Norpatagonia: el Fondo Editorial Neuquino" indaga las leyes y premiaciones implementadas por el gobierno de esa provincia desde 1989 hasta la actualidad con el objetivo de fomentar la publicación de libros de autores locales, a la vez que señala los sendos obstáculos para posicionarse en el mercado debido a los problemas en la distribución y la venta. De este trabajo resulta además, el interés por el abordaje de una de las periferias del campo editorial argentino, que permite reflexionar sobre los estados incompletos que a la fecha guarda el mapa de las ediciones nacionales.

El segundo sentido otorgado a la noción de catálogo se refiere al artefacto u objeto impreso que contiene y exhibe -de forma ostensible o velada- las decisiones del editor, desde sus propuestas culturales, políticoideológicas o estéticas hasta sus estrategias de mercadeo. Para algunos especialistas, los catálogos editoriales son básicamente productos destinados a la promoción, difusión y venta de libros ofertados por una casa. Sin embargo, si bien ofrecen datos comerciales, también informan acerca de la estructura del sello o de las colecciones, mediante textos e imágenes, el ideario de una dirección o gestión editorial, la posición que ocupa un autor e inclusive una colección en la estructura ampliada de esa casa y dentro de la constelación cultural de un país o región. La materialización de un catálogo puede utilizarse como obra de referencia de carácter documental o fuente primaria que aporta información bibliográfica, teniendo en consideración el contexto histórico de producción de la obra. En relación a estos aspectos, el trabajo de Marina Garone Gravier "Los catálogos editoriales como fuentes para el estudio de la bibliografía y la historia de la edición. El caso del Fondo de Cultura Económica" aborda esos 'impresos efímeros', ofreciendo precisiones conceptuales y metodológicas para su tratamiento documental e interpretación diacrónica. Uno de los aportes de dicho ensayo es la tipología proporcionada, tanto de los aspectos textuales como formales, de una amplia variedad de catálogos producidos por la casa editora objeto de estudio desde 1934 hasta 1994. El artículo permite observar algunas de las prácticas editoriales habituales y clásicas en torno a la producción de catálogos a través de un caso. Asimismo, debido al abordaje teórico del ensayo y a la dimensión de la producción en cuanto a 
la larga duración del repertorio estudiado de catálogos y vasos comunicantes de ese proyecto editorial con autores y sellos de otras latitudes, las consideraciones de su trabajo podrán ser utilizadas en el estudio de editoriales en el ámbito iberoamericano.

\section{RefERENCIAS}

Braudillard, J. ([1969] 2004). El sistema de los objetos. México: Siglo XXI.

Chartier, R. (1994). Elorden de los libros. Lectores, autores, bibliotecas en Europa entre los siglos XIV y XVIII. Barcelona: Gedisa.

Larraz Elorriaga, F. (2016). El catálogo como fuente primaria de la historia de la edición. En Seminario Internacional Hacia un marco metodológico y teórico para la historia de la edición. Alcalá, España.

\section{BY-NC-SA}

